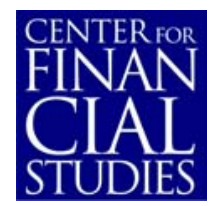

No. $2005 / 17$

The Optimal Inflation Buffer with a Zero Bound on Nominal Interest Rates*

Roberto Billi 


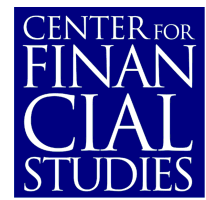

\section{Center for Financial Studies}

The Center for Financial Studies is a nonprofit research organization, supported by an association of more than 120 banks, insurance companies, industrial corporations and public institutions. Established in 1968 and closely affiliated with the University of Frankfurt, it provides a strong link between the financial community and academia.

The CFS Working Paper Series presents the result of scientific research on selected topics in the field of money, banking and finance. The authors were either participants in the Center's Research Fellow Program or members of one of the Center's Research Projects.

If you would like to know more about the Center for Financial Studies, please let us know of your interest.

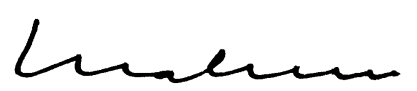

Prof. Dr. Jan Pieter Krahnen

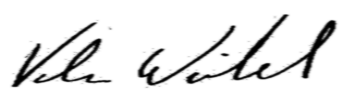

Prof. Volker Wieland, Ph.D. 


\title{
The Optimal Inflation Buffer with a Zero Bound on Nominal Interest Rates*
}

\author{
Roberto Billi ${ }^{1}$
}

\section{November 25, 2004}

\begin{abstract}
:
This paper characterizes the optimal inflation buffer consistent with a zero lower bound on nominal interest rates in a New Keynesian sticky-price model. It is shown that a purely forward-looking version of the model that abstracts from inflation inertia would significantly underestimate the inflation buffer. If the central bank follows the prescriptions of a welfaretheoretic objective, a larger buffer appears optimal than would be the case employing a traditional loss function. Taking also into account potential downward nominal rigidities in the price-setting behavior of firms appears not to impose significant further distortions on the economy.
\end{abstract}

JEL Classification: C63, E31, E52

Keywords: Inflation Inertia, Downward Nominal Rigidity, Nonlinear Policy, Liquidity Trap

\footnotetext{
* The background work for this paper was carried out in the Summer of 2004 while the author was visiting as a dissertation intern the Division of Monetary Affairs at the Federal Reserve Board; kind hospitality is gratefully acknowledged. The author would like to thank Klaus Adam, Günter Beck, Ben Bernanke, Michael Binder, Seth Carpenter, Bill English, Jon Faust, Ben Friedman, Dale Henderson, Jinill Kim, Dirk Krüger, Keith Küster, Andy Levin, Cyril Monnet, Athanasios Orphanides, Dave Reifschneider, Jeremy Rudd, Eric Swanson, Frank Smets and Volker Wieland for helpful comments and discussions.

${ }^{1}$ Correspondence: Center for Financial Studies, Taunusanlage 6, 60329 Frankfurt am Main, Germany, E-mail: billi@ifk-cfs.de, Homepage: http://www.rmbilli.com
} 


\section{Introduction}

The recent years have witnessed a general success of central banks of major world economies in conquering inflation. Consequently, a renewed interest has emerged among academics and policymakers in a more systematic analysis of how to conduct monetary policy in low inflation environments, where lower average levels of nominal interest rates increase the likelihood of the zero bound being a binding constraint. ${ }^{1}$ Questions that immediately arise are: How can the central bank stimulate aggregate demand in the economy if it cannot lower nominal interest rates any further? And what should the central bank do to minimize the chances that the economy might fall into a situation of zero nominal interest rates?

The relevant literature has been able to sketch the following answers to these questions: When zero nominal interest rates are reached, the central bank can still continue to reduce real rates and stimulate aggregate demand by generating inflationary expectations. ${ }^{2}$ To prevent the economy from falling into a situation of zero nominal rates in the first place, the central bank should sustain a higher long-run average rate of inflation than would be the case without the lower bound. In addition to adopting such an inflation 'buffer,' the central bank should act in a 'preemptive' fashion, turning more expansionary and aggressive already when adverse shocks threaten to push the economy into a situation of zero nominal rates. ${ }^{3}$

The main contribution of this paper is to show that there is a crucial aspect of the design of monetary policy in a low inflation, low interest rate

\footnotetext{
${ }^{1}$ In principle achieving negative nominal rates is feasible, e.g., if one is willing to give up free convertibility of deposits and other financial assets into cash or if one could levy a tax on money holdings, see Buiter and Panigirtzoglou (2003) and Goodfriend (2000). However, a general consensus on the applicability of such policy measures seems not to have been reached yet.

${ }^{2}$ The key insight that the management of private-sector expectations by the central bank can mitigate the effects of the zero lower bound can be traced back to Krugman (1998). Bernanke and Reinhart (2004) argue that central banks do understand the importance of influencing market expectations of future policy actions. Empirical evidence that the Federal Reserve has been successful in this is provided by Bernanke, Reinhart and Sack (2004).

${ }^{3} \mathrm{~A}$ more detailed review of the literature follows in section 2 .
} 
environment that so far has not been dealt with: What are the implications of a high degree of inflation persistence, as actually observed in major world economies, for the determination of the optimal inflation buffer and preemptive policy action?

To address this issue, the framework adopted is a version of the wellknown New Keynesian sticky-price model, where inflation is also partly determined by past inflation, see Clarida, Galí and Gertler (1999) and Woodford (2003). The model is calibrated to the U.S. economy accounting for the high degree of inflation persistence as actually observed in the data, e.g., Christiano, Eichenbaum and Evans (2001) and Giannoni and Woodford (2003). From a technical point of view, the policy problem as studied in this paper simultaneously addresses three specific features, each of which significantly aggravates its solution. These features are the occasionally binding constraint on the policy instrument, the standard conditions of uncertainty, and the forward-looking nature of the model. Only recently, nonlinear numerical methods apt to solving this general class of problems have been developed, see Adam and Billi (2003a) for the purely forward-looking case.

Anticipating the main findings, it is shown that the optimal inflation buffer is increasing in the degree of inflation inertia, and purely forwardlooking models may severely underestimate its relevance. Assuming the central bank aims at minimizing a traditional loss function would entail a somewhat smaller buffer, than with a welfare-theoretic objective. Taking also into account potential downward nominal rigidities in the price-setting behavior of firms appears not to increase significantly the buffer. Interestingly, at the lower bound output losses may be accompanied by inflation, rather than deflation, because of the forward-looking nature of expectations in the model. ${ }^{4}$

The remainder of this paper is structured as follows. Section 2 reviews the related literature. Section 3 introduces the policy problem and its calibration. Section 4 illustrates the optimal policy, thereby revealing the effects

\footnotetext{
${ }^{4}$ Demand shortfalls and deflation are features commonly associated with the concept of a 'liquidity trap.'
} 
of inflation inertia on the optimal buffer. Section 5 considers alternative policy objectives. Section 6 introduces potential downward nominal rigidity. Section 7 briefly concludes. The appendix explains the solution method and the numerical algorithm employed.

\section{Related Literature}

The relevance of the zero lower bound for the determination of the optimal inflation rate in the economy has been noted by Phelps (1972) and Summers (1991). The buffer role of inflation and preemptive policy action find support also in Bernanke (2000). Faust and Henderson (2004) argue that determining how large an inflation buffer to allow is a technical question and the answer may change over time as the economy changes; therefore, they suggest keeping the choice of the inflation target in the hands of the central bank and for revisiting it periodically.

A number of recent papers examine how monetary policy should be conducted in the presence of a zero lower bound on nominal interest rates. ${ }^{5}$ One strand of the literature examines the performance of simple policy rules. Among these are Fuhrer and Madigan (1997), Coenen, Orphanides and Wieland (2004), and Reifschneider and Williams (2000) that study dynamic rational expectation models employing simulation methods. Wolman (2004) adopts a general equilibrium framework. This set of papers shows that with a targeted inflation rate close enough to zero simple policy rules formulated in terms of inflation rates, e.g., the 'Taylor rule' (1993), can generate significant real distortions. ${ }^{6}$ Pursuing instead a target rate of inflation

\footnotetext{
${ }^{5}$ Rotemberg and Woodford (1998) and Smets (2003), among others, address the lower bound constraint only indirectly by penalizing policies resulting in exceedingly variable nominal interest rates. This approach has the advantage of preserving the simplicity of standard linear-quadratic approximation methods. But comes at the cost of neglecting the asymmetry that is inherent in the interest rate policy.

${ }^{6}$ Reifschneider and Williams (2000) and Wolman (2004) find also that simple policy rules formulated in terms of a price level target, rather than an inflation target, can yield a dramatic reduction of the real distortions associated with the zero lower bound. In fact, price level rules build in an offset to past deviations from the rule itself, introducing into the central bank's policy actions a form of 'history-dependence' that relates to policy
} 
larger than zero can reduce the distortions in the stochastic properties of the economy. But how to determine the optimal size of such an inflation target remains an open question, addressed by the current paper.

Another strand of the literature examines the design of optimal monetary policy in models with backward-looking expectations. Orphanides and Wieland (2000) and Kato and Nishiyama (2003) characterize optimal monetary policy in stochastic dynamic rational expectation models where privatesector expectations about future policy actions play no role. These papers show that 'preemptive' easing is optimal in the run-up to a binding lower bound even if the central bank cannot intervene in the economy through the expectational channel by promising inflation.

However, key to effective central-bank action is the 'management of expectations' on future policy actions, see Krugman (1998). Building on this insight, a further set of papers study the purely forward-looking version of the standard New Keynesian sticky-price model. Jung, Teranishi and Watanabe (2001) and Eggertsson and Woodford (2003) consider the deterministic setup and very special cases of the stochastic shock processes, respectively. But 'preemptive' easing of optimal policy arises from having uncertainty about the future state of the economy. Adam and Billi (2003a) offer a rigorous treatment of optimal policy design under standard conditions of uncertainty in the purely forward-looking model.

The optimal monetary policy in the New Keynesian sticky-price model when the central bank is unable to commit to future plans is characterized by Adam and Billi (2003b). ${ }^{7}$ Discretionary policy making gives rise to a downward bias in the average inflation rate. ${ }^{8}$ Aiming for a positive inflation target can alleviate the lower bound constraint, but has to be weighed against the additional welfare costs being imposed on the economy. Already a modest

making under commitment.

${ }^{7}$ Wether policymakers can and may want to credibly commit to future plans is currently subject of debate, see Orphanides (2003).

${ }^{8}$ Krugman (1998) seems to have been the first to note that under discretion the lower bound may generate a 'deflation bias.' 
degree of inflation inertia significantly amplifies the demand shortfalls and deflation that arise at zero nominal rates. Instead in the current paper it is shown that higher inflation indexation might lead to an inflationary path at the lower bound. This counter intuitive result is explained by the ability of the central bank to generate inflationary expectations under policy commitment.

In this paper the interest rate is assumed to be the only available policy instrument. ${ }^{9}$ The role of the exchange rate and of quantity-based monetary policies in mitigating the distortions imposed by the lower bound is analyzed, among others, by Auerbach and Obstfeld (2003), Coenen and Wieland (2003), McCallum (2003), and Svensson (2003). Eggertsson and Woodford (2004) study the implications of optimal fiscal policy in the form of distortionary taxation. These papers however do not address the issue of how to characterize the optimal inflation buffer.

\section{Model and Calibration}

This section introduces the optimal policy problem and illustrates the calibration to the U.S. economy.

\subsection{Monetary Policy Problem}

A standard dynamic general equilibrium framework with nominal rigidities from staggered price-setting behavior of firms is considered. It is well-known in the literature as the 'New Keynesian' model, as described by Clarida, Galí and Gertler (1999) and Woodford (2003).

Log-linearizing the model around the deterministic steady-state, apart from the zero lower bound on nominal interest rates, reduces it to a twoequation system: an aggregate-supply relation capturing the price-setting behavior of firms; and an intertemporal IS relation describing the private

\footnotetext{
${ }^{9}$ Indirectly, also 'promises' that have to be kept form past commitments can be thought of as policy instruments, see appendix A.1.
} 
expenditure decisions of households. ${ }^{10}$ This otherwise standard monetary policy problem is here augmented by explicitly imposing the lower bound, kept in its original nonlinear form.

The policy problem of the central bank is:

$$
\begin{aligned}
\max _{\left(y_{t}, \pi_{t}, i_{t}\right)}-E_{0} \sum_{t=0}^{\infty} \beta^{t}\left(\left(\pi_{t}-\theta \pi_{t-1}\right)^{2}+\alpha y_{t}^{2}\right) \\
\text { s.t. } \\
\pi_{t}=\frac{1}{1+\beta \theta}\left[\beta E_{t} \pi_{t+1}+\theta \pi_{t-1}+\lambda y_{t}\right] \\
y_{t}=E_{t} y_{t+1}-\sigma\left(i_{t}-E_{t} \pi_{t+1}-r_{t}^{n}\right) \\
r_{t}^{n}=\left(1-\rho_{r}\right) \bar{r}+\rho_{r} r_{t-1}^{n}+\varepsilon_{t}^{r} \\
i_{t} \geq 0
\end{aligned}
$$

where $\pi_{t}$ denotes the quarterly inflation rate and $y_{t}$ the output gap, i.e., the deviation of output from its 'natural' flexible-price equilibrium. The quarterly nominal interest rate $i_{t}$ is the instrument of monetary policy.

The welfare-theoretic objective of the central bank, equation (1), is a quadratic (second-order Taylor series) approximation to the expected utility of the representative household. Where $\beta \in(0,1)$ is the discount factor and the weight $\alpha>0$ depends on the underlying structure of the economy. ${ }^{11}$ The model abstract from the transaction frictions and money demand distortions associated with positive nominal interest rates.

Equation (2) is a deterministic aggregate-supply relation, that allows for backward-looking indexation of individual prices to an aggregate price in-

\footnotetext{
${ }^{10}$ The reader is referred to Woodford (2003) for further discussion of the foundations of the New Keynesian model.

${ }^{11}$ With inflation inertia from backward-looking indexation of individual prices to an aggregate price index, firms that do not reoptimize their prices raise them mechanically by an amount $\theta \pi_{t-1}$. To reduce the distortions associated with price dispersion it is thus the change in the rate of inflation, $\pi_{t}-\theta \pi_{t-1}$, rather than inflation, $\pi_{t}$, that has to be stabilized around zero, see Ch. 6 in Woodford (2003).
} 
dex. Where $\lambda>0$ is the slope parameter, that depends on the underlying structure of the economy, and $\theta \in(0,1)$ indicates the degree of indexation to the aggregate price index. For $\theta=0$ equation (2) reduces to the purely forward-looking case. For $\theta>0$ inflation is partly determined by lagged inflation, which becomes an endogenous state variable of the model. This follows Christiano, Eichenbaum and Evans (2001) in addressing the substantial criticism directed at the purely forward-looking version of the New Keynesian stick-price model for its inability to capture the high persistence that inflation displays in the data.

The model abstracts from so-called 'cost-push' shocks that would shift the aggregate-supply relation. ${ }^{12}$ Therefore, without a zero lower bound constraint on the nominal interest rate there would be no tension between the two goals of inflation and output stabilization. This simplifies the solution of the problem, since introducing exogenous 'cost-push' shocks would add an additional state variable to the model. ${ }^{13}$ It also has an important advantage in terms of interpreting the results. The distortions observed in the stochastic properties of the economy are arising only from the lower bound.

Moreover, equation (3) is a stochastic intertemporal IS relation, where $\sigma>0$ denotes the real interest rate elasticity of output. Equation (4) describes the evolution of the exogenous 'natural' real-rate of interest shock $r_{t}^{n} .{ }^{14}$ It is assumed to follow an $\mathrm{AR}(1)$ process with autoregressive coefficient $\rho_{r} \in(0,1)$ and equilibrium value $\bar{r}$. The innovation $\varepsilon_{t}^{r}$ is assumed normally distributed with zero mean. The quarterly discount factor is implied by the relation $\beta=(1+\bar{r})^{-1}$.

Equation (5) represents the zero lower bound on nominal interest rates, kept in its original nonlinear form. Importantly, in this otherwise linear-

\footnotetext{
${ }^{12}$ Such disturbances could be interpreted as variations over time in the degree of monopolistic competition between firms.

${ }^{13}$ The model already has four state variables, see appendix A.1, and solving it is technically challenging.

${ }^{14}$ The disturbance $r_{t}^{n}$ summarizes all shocks that under flexible prices generate time variation in the real interest rate. Therefore, it captures the combined effects of preference shocks, productivity shocks, and exogenous changes in government expenditure.
} 
quadratic policy problem certainty equivalence breaks down. The long-run average rate of inflation $\bar{\pi}$ does not necessarily coincide with the deterministic steady-state rate of inflation $\pi^{s s}$, in practice $\pi^{s s} \leq \bar{\pi}^{15}$ This lends to clarify that studying the approximated model log-linearized around the deterministic steady-state does not represent a limitation as serious as one might initially think.

A paramount advantage of focusing on the nonlinearity induced by the lower bound alone is that it economize in the dimension of the state space. A fully nonlinear setup would require instead an additional state variable to keep track over time of the higher-order effects of price dispersion, as shown by Schmitt-Grohé and Uribe (2003).

\subsection{Calibration to U.S. Economy}

The optimal monetary policy problem introduced in the previous section is calibrated to the U.S. economy. The baseline parametrization is summarized in table 1.

The values assigned to the structural parameters of the economy are taken from table 6.1 in Woodford (2003). Interestingly, the weight $\alpha$ derived from the underlying structure of the economy is equal to 0.003 quarterly. This is only a small fraction of unity that instead is commonly assumed in the literature on the evaluation of monetary policy rules, based on the idea that the central bank should give equal weight to its stabilization objectives.

In addition, following Christiano, Eichenbaum and Evans (2001) and the estimates of Giannoni and Woodford (2003), the degree of inflation indexation $\theta$ is set close to unity, namely 0.99 . This takes into account that in the limiting case of full inflation indexation $(\theta=1)$ the optimal nonlinear policy for the welfare-theoretic loss function, equation (1), is not well defined. The central bank would be stabilizing the pure change in the rate of inflation,

\footnotetext{
${ }^{15}$ The deterministic steady-state rate of inflation $\pi^{s s}$ is the inflation rate that would be observed when the state of the economy corresponds to the deterministic steady-state. Only if certainty equivalence were to hold then $\pi^{s s}=\bar{\pi}$.
} 
$\pi_{t}-\pi_{t-1}$, rather than inflation, $\pi_{t}$. There would be no tension between inflation stabilization and a higher long-run average rate of inflation in protecting the economy from the lower bound.

The parameters that describe the evolution of the exogenous real-rate shock $r_{t}^{n}$ are set to the estimates of Adam and Billi (2003a). An equilibrium value of $3.5 \%$ annually, implying a quarterly discount factor of 0.9913 , standard deviation $1.6 \%$ annually and autoregressive coefficient of 0.8 .

The robustness of the results obtained for the baseline calibration is checked by solving the monetary policy problem also under the alternative assumption of a much lower equilibrium value of the real-rate shock, say $2 \%$ annually. Lowering the equilibrium value is of interest since it is equivalent to increasing the variability of the real-rate disturbance, implying that the economy would be more often than usual in a situation of zero nominal rates. A lower equilibrium value of the real-rate shock may also be interpreted as due to a reduction in the expected growth rate of government expenditures.

\section{Optimal Policy}

The policy problem outlined in the previous section is solved assuming that the central bank can credibly commit to its policy plans. The solution method and the numerical algorithm employed are explained in appendixes A.1 and A.2, respectively. This section illustrates the main findings. All variables are expressed in terms of annualized percentage points.

\subsection{Buffer Role of Inflation}

Discussed for first are the effects of inflation indexation in the economy on the stochastic distribution of inflation. The model is nonlinear and certainty equivalence breaks down, therefore, the long-run average rate of inflation $\bar{\pi}$ will in general differ from the deterministic steady-state rate of inflation $\pi^{s s}$.

Depicted in each plot of figure 1 are two sets of statistics, one with the zero lower bound being imposed (ZLB) and another with the nominal interest 
rate allowed to become negative (LQ). The degree of inflation indexation $\theta$ ranges from zero, corresponding to the purely forward-looking case, to the baseline value of 0.99 implying almost full indexation.

The top panel of figure 1 shows that the optimal long-run average rate of inflation consistent with the lower bound is increasing in the degree of inflation indexation. ${ }^{16}$ The inflation buffer, from less than 1 basis point annually in the purely-forward looking case, rises to about 79 basis points annually with almost full inflation indexation. This reveals that inflation inertia in the economy needs to be taken appropriately into account in assessing the practical significance of the buffer role of inflation.

The middle panel of figure 1 depicts the standard deviation of inflation over the degree of inflation indexation. Together with the first panel, this shows that there is a positive relation between the inflation buffer and the standard deviation of inflation. A positive correlation between the level and the volatility of inflation is a well-known empirical feature of the data. The model abstracts from exogenous 'cost-push' shocks, therefore, the inflation buffer and the volatility of inflation are due solely to the policy trade-off that arises from the zero lower bound.

The bottom panel of figure 1 illustrates how inflation indexation translates into actual inflation persistence in the economy. The autocorrelation of inflation is higher with the zero lower bound, than without. The asymmetry in the stochastic distribution of inflation arising from the lower bound adds inertia to the inflation process. In the purely-forward looking case the autocorrelation of inflation is about 0.73 with the lower bound and only about 0.49 without. However, for almost full inflation indexation in the economy it rises above 0.99 both with and without the lower bound; the difference is almost indistinguishable. Interestingly, this implies that a high level of inflation inertia as observed in the data would be consistent with the central bank either taking into account the lower bound or neglecting it.

\footnotetext{
${ }^{16}$ The statistics reported for the stochastic distribution of inflation, i.e., mean, standard deviation and autocorrelation, are computed from a stochastic simulation of one-million model periods on the optimal policy, see appendix A.2.
} 
To further clarify the practical relevance of the inflation buffer, figure 2 depicts the average occurrence of zero nominal interest rates as a function of the degree of inflation indexation in the economy. Both with the zero lower bound being imposed (ZLB) and without (LQ). Taking into account the lower bound, a higher degree of indexation in the economy entails that zero nominal interest rates occur less often. For the purely-forward looking case the lower bound would bind about one quarter every 15 years on average. While for almost full inflation indexation zero nominal rates are encountered about one quarter every 218 years on average only.

Figure 2 also reveals that for a low degree of inflation indexation zero nominal rates occur more frequently if the zero lower bound is being imposed. Instead, for a sufficiently high degree of inflation indexation zero nominal rates occur less frequently if there is a lower bound. ${ }^{17}$

\subsection{Policy Responses}

Figure 3 displays optimal policy responses $(y, \pi, i)$ and optimal expectation responses $\left(E y^{\prime}, E \pi^{\prime}, E i^{\prime}\right)$ to a real-rate shock. ${ }^{18}$ Depicted in each plot are three sets of optimal responses. With the zero lower bound imposed (ZLB, $\theta=0$ or 0.99 ) and with the nominal interest rate allowed to become negative (LQ). Interestingly, the linear-quadratic approximation of the policy problem is independent of the degree of inflation indexation $\theta$, since the model abstracts from 'cost-push' shocks.

In particular, figure 3 shows that without lower bound a real-rate shock would not generate any policy trade-off, i.e., the required real-rate could be implemented, at least theoretically, through variations in the nominal rate alone, leaving both output at potential and inflation at zero. Instead, taking

\footnotetext{
${ }^{17}$ Section 4.3 shows that a higher degree of inflation indexation reduces the amount of preemptive easing of nominal interest rates.

${ }^{18}$ Policies and expectations are displayed for a range of \pm 4 unconditional standard deviations of the real-rate shock. To improve readability, the other state variables not shown on the $x$-axes are all set to zero. This assumes that the monetary authority faces no past commitments and that there was no inflation in the previous period, i.e., $\mu^{1}=\mu^{2}=\pi_{-1}=0$, see appendix A.1.
} 
into account the zero lower bound, for a sufficiently strong adverse realrate shock the central bank will not be able to further lower nominal rates once the bound is binding. As depicted, with a zero (more generally, with a sufficiently small) degree of inflation indexation in the economy, output starts falling below potential and deflation arises. These are features commonly associated with the concept of a 'liquidity trap.' However, if the degree of inflation indexation is sufficiently high optimal policy generates inflation, rather than deflation

This striking result of output losses being associated with rising inflation due to the presence of the zero lower bound on nominal rates can be interpreted in the follow manner. Once the lower bound is reached, to achieve a reduction in the real-rate of interest and stimulate aggregate demand in the economy, the central bank needs to promise future inflation. As one may infer from the aggregate-supply relation, equation (2), the higher is the degree of inflation indexation in the economy the more inflation has to be promised in order to contain the deflationary pressure. A larger inflation promise may not only reduce the deflationary pressure but actually drive inflation up. Importantly, this outcome relies on the assumption that the central bank can credibly commit to carry out an inflationary policy in the future, after the economy has evolved out of the binding lower bound. ${ }^{19}$

\subsection{Preemptive Easing}

Figure 4 illustrates in greater detail the optimal nominal interest rate response, $i$, and also the optimal real-rate response, $i-E \pi^{\prime}$, to a real-rate shock. Again, depicted in each plot are three sets of optimal responses. With the zero lower bound imposed (ZLB, $\theta=0$ or 0.99 ) and with the nominal interest rate allowed to become negative (LQ).

\footnotetext{
${ }^{19}$ Adam and Billi (2003b) study optimal monetary policy in a similar model but under discretion, i.e., assuming that the central bank is unable to influence expectations of the future course of policy. They show that the zero lower bound entails a deflation bias, rather than an inflation buffer. Moreover, inflation persistence causes the real interest rate to remain undesirably high for a longer period of time, significantly increasing the amount of deflation associated with adverse real-rate shocks.
} 
The two panels of figure 4 reveal that 'preemptive' easing of nominal (and real) interest rates is optimal in the run-up to a binding lower bound. Nominal (and real) rates are lowered more rapidly than without the lower bound. To understand why this is the case one should note, looking back at figure 3 , in response to an adverse real-rate shock expected output is falling already before the lower bound is actually reached, while output is yet at potential. This is consistent with the intertemporal IS relation, equation (3). Once the lower bound starts to bind and the central bank is promising future inflation, output is expected to rise above potential. Then a further slide in output commences to drag down also expected output.

Furthermore, the top panel of figure 4 discloses that a higher degree of inflation indexation in the economy reduces the optimal amount of 'preemptive' easing of nominal rates. Expected output needs to falls by less while output is yet at potential (cfr. figure 3). And the lower panel shows that the central bank needs to generate a smaller reduction in the real interest rate once at the lower bound, since it promises more future inflation (cfr. figure $3)$.

\subsection{Dynamic Responses}

Figure 5 displays the dynamic responses of the economy $(y, \pi-\bar{\pi}, i$,$) to$ a real-rate shock, namely -3 unconditional standard deviations below its baseline equilibrium value of $3.5 \%$ annually. ${ }^{20}$ This represents a relatively large adverse real-rate shock, that would push it down to $-1.3 \%$ annually.

As argued by Krugman (1998), negative real rates are plausible even if the marginal product of physical capital remains positive. For instance agents

\footnotetext{
${ }^{20}$ Since in this nonlinear model certainty equivalence fails to hold, results are discussed in terms of the implied 'mean dynamics' in response to the real-rate shock, instead of the more familiar deterministic impulse responses. The mean dynamics are computed as the average of 10,000 stochastic simulations. The initial values of the other state variables are set equal to their respective unconditional average values. Setting them instead to conditional average values consistent with the real-rate shock does not make a noticeable difference.
} 
may require a large equity premium, e.g., historically observed in the U.S., or the price of physical capital may be expected to decrease.

Depicted in each plot of figure 5 are two sets of mean responses, with the degree of inflation indexation in the economy, $\theta$, being either 0 or the baseline $99 \%$. Both sets with the lower bound. The figure clarifies that with more inflation indexation in the economy inflation and inflation promises of the central bank rise higher above average and are kept high for longer. ${ }^{21}$ For almost full indexation after five quarters inflation rises more than 20 basis points annually above its long-run average value; then converges back to average only very slowly. Interestingly, inflation is still above average a long time after real and nominal interest rates have returned to their respective average values. In contrast, with no (more generally, with a lower degree of) inflation indexation in the economy inflation rises by less and returns more rapidly, than real and nominal interest rates, to its long-run average value.

\section{Traditional Loss Function}

The previous section illustrated the main findings of the model when assuming that the central bank follows the prescriptions of a welfare-theoretic loss function. As a robustness exercise, in this section an alternative specification of the loss function is employed. Table 2 summarizes the implications for the optimal inflation buffer.

The monetary policy problem is solved replacing the welfare-theoretic objective of the central bank, equation (1), with a loss function more commonly employed in the monetary policy literature:

$$
\max _{\left(y_{t}, \pi_{t}, i_{t}\right)}-E_{0} \sum_{t=0}^{\infty} \beta^{t}\left(\pi_{t}^{2}+\alpha y_{t}^{2}\right)
$$

\footnotetext{
${ }^{21}$ The mean path of inflation tells also the evolution of expected inflation, since the average rate of inflation in period $n$ corresponds to the average rate of inflation that in period $n^{\prime}<n$ is expected for period $n$. The same can be said for all the mean responses of the economy.
} 
where it is inflation, $\pi_{t}$, instead of the change in the rate of inflation, $\pi_{t}-$ $\theta \pi_{t-1}$, that should be stabilized around zero.

As explained in section 3.2, the weight $\alpha$ derived from the underlying structure of the economy is equal to 0.003 quarterly. This is only a small fraction of unity that instead is commonly assumed in the literature, based on the idea that the central bank should give equal weight to its stabilization objectives. Therefore, the monetary policy problem is solved both for the baseline value of the weight $\alpha=0.003$ and for $\alpha=1$.

Table 2 reports the optimal inflation buffer corresponding to the three alternative specifications of the loss function, i.e., the 'welfare-theoretic,' the 'traditional' and the traditional with 'equal weight.' The table shows the inflation buffer for the baseline value of the equilibrium real-rate of $3.5 \%$. Also shown is the buffer for a much lower equilibrium value of $2 \%$, implying that the economy would be more often than usual in a situation of zero nominal rates. With the traditional loss function the buffer is less than 1 basis point annually for the baseline calibration; rising only to 4 basis points annually for the lower equilibrium real-rate. This is in sharp contrast with the welfare-theoretic case where the buffer is much higher at about $0.8 \%$ annually for the baseline calibration; it rises to almost $1.9 \%$ annually for the lower equilibrium real-rate. The equal weight loss function appears an intermediate case in terms of the buffer, being at about $0.1 \%$ annually for the baseline and about $0.5 \%$ annually for the lower equilibrium real-rate.

Figure 6 displays optimal policy responses $(y, \pi, i)$ to a real-rate shock, with the traditional loss function in the left-hand panel and with the traditional loss function with equal weight in the right-hand panel. Depicted in each plot are three sets of optimal responses. With the zero lower bound imposed (ZLB, $\theta=0$ or 0.99 ) and with the nominal interest rate allowed to become negative (LQ). The figure shows that with the equal weight the maximum output losses to and adverse real-rate shock would be roughly only one third of those with the traditional loss function. Because more volatility of inflation is tolerated by the central bank, relative to volatility of output. 
This also explains why the inflation buffer is larger with the equal weight.

Figure 7 illustrates in greater detail the optimal nominal interest rate response, $i$, and also the optimal real-rate response, $i-E \pi^{\prime}$, to a real-rate shock. Again, with the traditional loss function in the left-hand panel and with the equal weight in the right-hand panel. It can be seen that the traditional loss function entails far more 'preemptive' easing of nominal interest rates. This is the case since the inflation buffer is lower and the risk of hitting the lower bound is greater.

Figure 8 depicts the dynamic responses of the economy $(y, \pi-\bar{\pi}, i$,$) to$ a real-rate shock, namely -3 unconditional standard deviations below its baseline equilibrium value of $3.5 \%$ annually. Again, with the traditional loss function in the left-hand panel and with the equal weight in the right-hand panel. As shown, with the equal weight inflation would rise higher above its long-run average value, then converges back to average at a lower pace. The central bank is thus more successful in generating inflationary expectations.

\section{Downward Nominal Rigidity}

As a further robustness exercise, in this section the policy problem is solved taking also into account potential downward nominal rigidity in the pricesetting behavior of firms. Table 3 summarizes the implications on the optimal inflation buffer.

Besides the zero lower bound, another important argument for a positive long-run average rate of inflation in the economy is a potential asymmetry in the price-setting behavior of firms, e.g., Summers (1991) and Krugman (1998). This reflects the view that a positive rate of inflation may facilitate wage adjustments in the economy when workers show resistance to wage bargains requiring declines in nominal compensation (even if real wages were to remain unchanged or rise because of declining aggregate prices). Resistance to wage declines places upward pressure on the average level of real wage 
costs to firms, that may be inclined to pass them on to their prices, leading to higher inflation at the aggregate level. ${ }^{22}$

A direct way of capturing the effects on the economy of downward nominal rigidity is to generalize the objective of the central bank, equation (1), rendering it asymmetric as follows:

$$
\max _{\left(y_{t}, \pi_{t}, i_{t}\right)}-E_{0} \sum_{t=0}^{\infty} \beta^{t}\left(\left(\pi_{t}-\theta \pi_{t-1}\right)^{2}+c \pi_{t}^{2}+\alpha y_{t}^{2}\right)
$$

where $c=0$ if $\pi_{t} \geq 0$ and $c \geq 0$ if $\pi_{t}<0$. Therefore, if $\pi_{t} \geq 0$ the asymmetric objective, equation (7), collapses to its earlier quadratic expression (1). Instead, if $\pi_{t}<0$ a decline in the rate of inflation is more costly to the economy than an equivalent increase in inflation.

In the particular case of the 'traditional' loss function, introduced in section 5, the asymmetric objective is 'piecewise quadratic' in $\pi_{t} \cdot{ }^{23}$ As an illustrative example, the inflation component of the loss function is depicted in figure 9 for an extreme value of $c=1$ if $\pi_{t}<0$. This would imply that a decline in the rate of inflation is $100 \%$ more costly to the economy than an equal but opposite increase.

The model is solved with the asymmetric objective, equation (7), assuming $c=1$ if $\pi_{t}<0$. Table 3 reports the optimal inflation buffer corresponding to the three alternative specifications of the loss function, i.e., the 'welfaretheoretic,' the 'traditional' and the traditional with 'equal weight.' The table shows that taking also into account the additional distortions due to potential downward nominal rigidities in the price-setting behavior of firms can potentially increase further the inflation buffer. However, it appears not to

\footnotetext{
${ }^{22}$ For an influential study on the sources and implications of downward nominal rigidity see Akerlof, Dickens and Perry (1996). The authors present empirical and simulation-based evidence supporting the prevalence of downward nominal rigidity in the U.S. economy and its significance for the economy's performance, suggesting that an optimal inflation target for monetary policy is greater than zero.

${ }^{23}$ The idea of introducing a piecewise quadratic criterion function in an economic policy optimization framework finds an earlier treatment in Friedman (1975), Ch. 7, motivated within the context of an international balance of payments example.
} 
have major implications beyond the effects already due to the zero lower bound.

\section{Conclusions}

This paper characterizes optimal monetary policy in a New Keynesian stickyprice model with inflation inertia when nominal interest rates are bounded below by zero. It is assumed that the central bank can credibly commit to its policy plans. The model is calibrated to the U.S. economy and solved employing nonlinear numerical methods.

A main finding is that the optimal long-run average rate of inflation in the economy consistent with the zero lower bound is increasing in the degree of inflation indexation. Therefore, a purely forward-looking version of the model may severely underestimate the relevance of such an optimal inflation buffer. For a reasonable calibration to the U.S. economy the model prescribes a buffer of about $0.8 \%$ annually. A lower equilibrium value of the real-rate shock, say $2 \%$ annually, could imply an even larger buffer of about $1.9 \%$ annually. Replacing the welfare-theoretic loss function of the central bank with a traditional objective, it appears that a less pronounced buffer would suffice. The model is solved also introducing an asymmetry in the inflation objective of the central bank to take into account potential downward nominal rigidity in the price-setting behavior of firms. This seems not to add significantly to the inflation buffer.

These results highlight a number of fruitful avenues for future research. First, the model abstracts from cost-push shocks that would shift the aggregatesupply relation. It would be interesting to study the practical relevance of introducing this further distortion into the economy, but would require further progress in the numerical methodology developed. Second, other sources of frictions could be introduced in the model, e.g., sticky-wages, again pending improvement in the numerical methods employed. Third, the interest rate is assumed to be the only available policy instrument. It would be useful to study the role of the exchange rate and distortionary taxation in 
mitigating the distortions imposed by the lower bound. Fourth, comparing the optimal nonlinear policy with the performance of simple policy rules is clearly of interest.

\section{A Appendix}

This appendix illustrates the solution method used for solving the optimal policy problem and the numerical algorithm employed.

\section{A.1 Solving the Model}

The optimal monetary policy problem, equations (1)-(5), is not recursive, since constraints (2) and (3) involve forward-looking variables. ${ }^{24}$. However, a recursive formulation can be derived based on the corresponding Lagrangian of the infinite horizon problem.

Specifically, applying the method proposed by Marcet and Marimon (1998) the problem can be reformulated as:

$$
\begin{aligned}
W\left(s_{t}\right)=\inf _{x_{1}} \sup _{x_{2}}\left\{h\left(s_{t}, x_{1 t}, x_{2 t}\right)+\beta E_{t} W\left(s_{t+1}\right)\right\} \\
\text { s.t. } \\
\mu_{t+1}^{1}=\gamma_{t}^{1}, \quad \mu_{0}^{1}=0 \\
\mu_{t+1}^{2}=\gamma_{t}^{2}, \quad \mu_{0}^{2}=0 \\
r_{t+1}^{n}=\left(1-\rho_{r}\right) \bar{r}+\rho_{r} r_{t}^{n}+\varepsilon_{t+1}^{r} \\
i_{t} \geq 0
\end{aligned}
$$

where $s=\left(\mu^{1}, \mu^{2}, \pi_{-1}, r^{n}\right) \subset R^{4}$ is the state space, $x_{1}=\left(\gamma^{1}, \gamma^{2}\right)$ and $x_{2}=$ $(y, \pi, i)$ are the vectors of controls, and the one-period return is

\footnotetext{
${ }^{24}$ Solving the optimal policy problem with downward nominal rigidity in the price setting behavior of firms, in section 6, the quadratic loss function of the monetary authority, equation (1), is replaced with the generalized asymmetric objective, equation (7).
} 


$$
\begin{aligned}
h\left(s_{t}, x_{1 t}, x_{2 t}\right) \equiv & -\alpha y_{t}^{2}-\left(\pi_{t}-\theta \pi_{t-1}\right)^{2} \\
& +\gamma_{t}^{1}\left(\pi_{t}-\frac{1}{1+\beta \theta}\left(\theta \pi_{t-1}+\lambda y_{t}\right)\right)-\mu_{t}^{1} \frac{1}{1+\beta \theta} \pi_{t} \\
& +\gamma_{t}^{2}\left(y_{t}+\sigma\left(i_{t}-r_{t}^{n}\right)\right)-\mu_{t}^{2} \frac{1}{\beta}\left(\sigma \pi_{t}+y_{t}\right)
\end{aligned}
$$

The reformulated problem, equation (8), is a recursive saddle point functional equation, i.e., a generalized Bellman equation. It requires maximization with respect to the policies $x_{2}=(y, \pi, i)$; and minimization with respect to the Lagrange multipliers $x_{1}=\left(\gamma^{1}, \gamma^{2}\right)$ of the constraints (2) and (3) that contain forward-looking variables.

Besides the two original state variables $\left(\pi_{-1}, r^{n}\right)$, there are now two additional co-state variables $\left(\mu^{1}, \mu^{2}\right)$, given by the lagged values of the Lagrange multipliers. These can be interpreted as measuring the marginal value costs of 'promises' that have to be kept from past policy commitments.

Associated with the policy functions are the expectation functions:

$$
\begin{aligned}
E_{t} y_{t+1} & =\int y_{t}\left(\gamma_{t}^{1}, \gamma_{t}^{2}, \pi_{t},\left(1-\rho_{r}\right) \bar{r}+\rho_{r} r_{t}^{n}+\varepsilon_{t+1}^{r}\right) f\left(\varepsilon_{t+1}^{r}\right) d\left(\varepsilon_{t+1}^{r}\right) \\
E_{t} \pi_{t+1} & =\int \pi_{t}\left(\gamma_{t}^{1}, \gamma_{t}^{2}, \pi_{t},\left(1-\rho_{r}\right) \bar{r}+\rho_{r} r_{t}^{n}+\varepsilon_{t+1}^{r}\right) f\left(\varepsilon_{t+1}^{r}\right) d\left(\varepsilon_{t+1}^{r}\right) \\
E_{t} i_{t+1} & =\int i_{t}\left(\gamma_{t}^{1}, \gamma_{t}^{2}, \pi_{t},\left(1-\rho_{r}\right) \bar{r}+\rho_{r} r_{t}^{n}+\varepsilon_{t+1}^{r}\right) f\left(\varepsilon_{t+1}^{r}\right) d\left(\varepsilon_{t+1}^{r}\right)
\end{aligned}
$$

where $f(\cdot)$ is the probability density function of the stochastic shock innovation $\varepsilon^{r}$. Assuming normality of the innovation, the expectation functions can be approximated by Gaussian-Hermite quadrature, as explained in appendix A.2.

\section{A.2 Numerical Algorithm}

One has to rely on nonlinear numerical methods to solve for the value function and optimal policy functions of the reformulated problem, equation (8). In particular, the collocation method can be employed. ${ }^{25}$

\footnotetext{
${ }^{25}$ For more detailed expositions of the collocation method see, e.g., Ch. 11 in Judd (1998) and Ch.s 6 and 9 in Miranda and Fackler (2002).
} 
In particular, the state space $s=\left(\mu^{1}, \mu^{2}, \pi_{-1}, r^{n}\right) \subset R^{4}$ is discretized into a set of $N$ collocation nodes $\aleph=\left\{s_{n} \mid n=1, \ldots, N\right\}$, where $s_{n} \in s$. The value function $W(\cdot)$ is interpolated over the collocation nodes $s_{n}$ by using a four dimensional cubic spline $\phi(\cdot)$ and choosing basis coefficients $c_{n}$ such that

$$
W\left(s_{n}\right) \approx \sum_{n=1}^{N} c_{n} \phi\left(s_{n}\right)
$$

Equation (9) is an approximation to the left-hand side of the reformulated problem, equation (8). Then to evaluate the right-hand side of equation (8) one approximates the expected value $E W\left(g\left(s_{n}, x_{1}, x_{2}, \varepsilon\right)\right)$, where $g(\cdot)$ denotes the state transition function, $x_{1}=\left(\gamma^{1}, \gamma^{2}\right)$ and $x_{2}=(y, \pi, i)$ are the vectors of controls, and $\varepsilon$ is the innovation of the stochastic shock process. Assuming normality of the innovation, the expected value function can be approximated by Gaussian-Hermite quadrature, which involves discretizing the shock distribution into a set of quadrature nodes $\varepsilon_{m}$, and associated probability weights $\omega_{m}$, for $m=1, \ldots, M .^{26}$

Substituting the collocation equation (9) for the value function $W(g(\cdot))$, the right-hand side of the reformulated problem, equation (8), can be approximated over the collocation nodes $s_{n}$ as

$$
\operatorname{RHS}\left(s_{n}\right) \approx \inf _{x_{1}} \sup _{x_{2}}\left\{h\left(s_{n}, x\right)+\beta \sum_{m=1}^{M} \sum_{n=1}^{N} \omega_{m} c_{n} \phi\left(g\left(s_{n}, x, \varepsilon_{m}\right)\right)\right\}
$$

The minimization/maximization with respect to $x=\left(x_{1}, x_{2}\right)$ in problem (10) may be solved using a standard Quasi-Newton optimization method, by taking into account the bounded control $i_{t} \geq 0$. This delivers $R H S(\cdot)$ and the policy functions $x(\cdot)$ at the collocation nodes $s_{n}$.

Finally, equating equations (9) and (10) at each collocation node $s_{n}$ delivers an approximation to the reformulated problem, equation (8). This

\footnotetext{
${ }^{26}$ For details on applying Gaussian-Hermite quadrature see, e.g., Ch. 7 in Judd (1998).
} 
defines a nonlinear equations system with unknown basis coefficients $c_{n}$ that can compactly expressed in vector form as the collocation equation

$$
\Phi c_{n}=\operatorname{RHS}\left(c_{n}\right)
$$

The collocation equation (11) may be solved using any nonlinear equation solution method. In particular, one can rewrite the collocation equation as a fixed-point problem $c_{n}=\Phi^{-1} R H S\left(c_{n}\right)$ and employ function iteration, with iterative update rule

$$
c_{n} \longleftarrow \Phi^{-1} R H S\left(c_{n}\right)
$$

Alternatively, the collocation equation can be rewritten as a rootfinding problem $\Phi c_{n}-R H S\left(c_{n}\right)=0$ and solved using Newton's method, which implies the iterative update rule

$$
c_{n} \longleftarrow c_{n}-\left[\Phi-R H S^{\prime}\left(c_{n}\right)\right]^{-1}\left[\Phi c_{n}-\operatorname{RHS}\left(c_{n}\right)\right]
$$

where $R H S^{\prime}\left(c_{n}\right)$ is the $n \times n$ Jacobian of $R H S(\cdot)$ at $c_{n}$.

The Algorithm proceeds as follows:

Step 1: Choose the degree of approximation $N$ and $M$ and set the appropriate collocation and quadrature nodes. Guess an initial basis coefficient vector $c_{n}^{0}$.

Step 2: Iterate on (12) or (13) and update the basis coefficient vector $c_{n}^{k}$ to $c_{n}^{k+1}$.

Step 3: Stop if $\max \left|c_{n}^{k}-c_{n}^{k+1}\right|<\tau$, where $\tau>0$ is a convergence tolerance level. Otherwise repeat step 2.

Once convergence is achieved the accuracy of the solution has to be checked. For this, define the residual function 


$$
R\left(s_{r}\right)=R H S\left(c_{r}\right)-\sum_{n=1}^{R} c_{n} \phi\left(s_{r}\right)
$$

that measures the approximation error between the right- and left-hand sides of the reformulated problem, equation (8), at an arbitrary grid of nodes $\Re=\left\{s_{r} \mid r=1, \ldots, R\right\}$, where $s_{r} \in S$ and $\Re \cap \aleph=\emptyset$. And check the maximum approximation error, $\max |R(\cdot)|$, over the grid of nodes $s_{r}$.

For the baseline calibration the optimal monetary policy problem is solved using Newton's method, setting $N=3375$ and $M=9$. Relatively more nodes are placed in areas of the state space where the value and policy functions display a higher degree of curvature and kinks, respectively. It is important to economize in this way assigning the nodes since the problem has a four dimensional state space and is challenging to solve. The support of the collocation nodes is chosen to cover \pm 4 unconditional standard deviations of the exogenous state $\left(r^{n}\right)$ and to insure that all values of the endogenous states $\left(\mu^{1}, \mu^{2}, \pi_{-1}\right)$ lie inside the state space when using the solution to stochastically simulate one-million model periods. Since this can only be verified after convergence is achieved some experimentation is necessary. The data generated by the simulation is then used to compute the statistics describing the stochastic distribution of the optimal policy.

The initial guess for the basis coefficient vector $c_{n}^{0}$ is set to the solution of the problem without zero lower bound. The tolerance level is $\tau=1.49 \cdot 10^{-8}$, i.e., the square root of machine precision. Convergence and the computation of the residual function takes about $1 / 2$ hour on a Pentium IV with $3.0 \mathrm{GHz}$. The maximum approximation error is less than 0.0008 , where $\Re$ contained more than 35, 000 nodes.

\section{References}

Adam, Klaus and Roberto M. Billi, "Optimal Monetary Policy under Commitment with a Zero Bound on Nominal Interest Rates," ECB Working Paper No. 3rr, July 2003. 
_ and _ _ , "Optimal Monetary Policy under Discretion with a Zero Bound on Nominal Interest Rates," ECB Working Paper No. 380, August 2003.

Akerlof, George A., William T. Dickens, and George L. Perry, "The Macroeconomics of Low Inflation," Brookings Papers on Economic Actvity, 1996, 1, 1-59.

Auerbach, Alan J. and Marurice Obstfeld, "The Case for Open-Market Purchases in a Liquidity Trap," NBER Working Paper No. 9814, 2003.

Bernanke, Ben S., "Deflation: Making Sure 'It' Doesn't Happen Here," 2000. Remarks before the National Economists Club, Washington. D.C., November 21, 2002, available at www.federalreserve.gov.

_ and Vincent R. Reinhart, "Conducting Monetary Policy at Very Low Short-Term Interest Rates," AEA Papers and Proceedings, 2004, $94(2), 85-90$.

__ _ _ a a a Brian P. Sack, "Monetary Policy Alternatives at the Zero Bound: An Empirical Assessment," FEDS Working Paper No. 48, 2004.

Buiter, Willem H. and Nikolaos Panigirtzoglou, "Overcoming the Zero Bound on Nominal Interest Rates with Negative Interest on Currency: Gesell's Solution," Economic Journal, 2003, 113, 723-746.

Christiano, Lawrence J., Martin S. Eichenbaum, and Charles L. Evans, "Nominal Rigidities and the Dynamic Effects of a Shock to Monetary Policy," NBER Working Paper No. 8403, 2001.

Clarida, Richard, Jordi Galí, and Mark Gertler, "The Science of Monetary Policy: Evidence and Some Theory," Journal of Economic Literature, 1999, 37, 1661-1707.

Coenen, Günter and Volker Wieland, "The Zero-Interest-Rate Bound and the Role of the Exchange Rate for Monetary Policy in Japan," Journal of Monetary Economics, 2003, 50, 1071-1101. 
Athanasios Orphanides, and Volker Wieland, "Price Stability and Monetary Policy Effectiveness When Nominal Interest Rates are Bounded at Zero," Advances in Macroeconomics, 2004, 4 (1), Article 1.

Eggertsson, Gauti and Michael Woodford, "Optimal Monetary Policy in a Liquidity Trap," NBER Working Paper No. 9968, 2003.

_ _ and _ _ "Optimal Monetary and Fiscal Policy in a Liquidity Trap," NBER Working Paper No. 10840, 2004.

Faust, Jon and Dale W. Henderson, "Is Inflation Targeting BestPractice Monetary Policy?," IFDP Working Paper No. 80\%, 2004.

Friedman, Benjamin M., Economic Stabilization Policy: Methods in Optimization, New York: American Elsevier Publishing Company, INC., 1975.

Fuhrer, Jeffrey C. and Brian F. Madigan, "Monetary Policy When Interest Rates are Bounded at Zero," Review of Economics and Statistics, 1997, 79, 573-585.

Giannoni, Marc P. and Michael Woodford, "Optimal Inflation Targeting Rules," NBER Working Paper No. 9939, 2003.

Goodfriend, Marvin, "Overcoming the Zero Bound on Interest Rate Policy," Journal of Money Credit and Banking, 2000, 32 (4,2), 1007-1035.

Judd, Kenneth L., Numerical Methods in Economics, Cambridge: MIT Press, 1998.

Jung, Taehun, Yuki Teranishi, and Tsutomu Watanabe, "Zero Bound on Nominal Interest Rates and Optimal Monetary Policy," Kyoto Institute of Economic Research Working Paper No. 525, 2001.

Kato, Ryo and Shinichi Nishiyama, "Optimal Monetary Policy When Interest Rates are Bounded at Zero," Bank of Japan Mimeo, 2003. 
Krugman, Paul R., "It's Baaack: Japan's Slump and the Return of the Liquidity Trap," Brookings Papers on Economic Activity, 1998, 49(2), 137-205.

Marcet, Albert and Ramon Marimon, "Recursive Contracts," Universitat Pompeu Fabra Working Paper, 1998.

McCallum, Bennett T., "Japanese Monetary Policy, 1991-2001," Federal Reserve Bank of Richmond Economic Quarterly, 2003, 89/1.

Miranda, Mario J. and Paul L. Fackler, Applied Computational Economics and Finance, Cambridge, Massachusetts: MIT Press, 2002.

Orphanides, Athanasios, "Monetary Policy in Deflation: The Liquidity Trap in History and Practice," Federal Reserve Board Mimeo, 2003.

and Volker Wieland, "Efficient Monetary Policy Design Near Price Stability," Journal of the Japanese and International Economies, 2000, 14, 327-365.

Phelps, Edmund S., Inflation Policy and Unemployment Theory, London: Macmillian, 1972.

Reifschneider, David and John C. Williams, "Three Lessons for Monetary Policy in a Low-Inflation Era," Journal of Money Credit and Banking, 2000, 32 (4,2), 936-966.

Rotemberg, Julio J. and Michael Woodford, "An Optimization-Based Econometric Model for the Evaluation of Monetary Policy," NBER Macroeconomics Annual, 1998, 12, 297-346.

Schmitt-Grohé, Stephanie and Martín Uribe, "Optimal Simple and Implementable Monetary and Fiscal Rules," Duke University Mimeo, 2003.

Smets, Frank, "Maintaining Price Stability: How Long is the Medium Term?," Journal of Monetary Economics, 2003, 50, 1293-1309. 
Summers, Lawrence, "Panel Discussion: Price Stability: How Should Long-Term Monetary Policy Be Determined?," Journal of Money Credit and Banking, 1991, 23, 625-631.

Svensson, Lars E. O., "Escaping from a Liquidity Trap and Deflation: The Foolproof Way and Others," Journal of Economic Perspectives, 2003, 17 (4), 145-166.

Taylor, John B., "Discretion versus Policy Rules in Practice," CarnegieRochester Conference Series on Public Policy, 1993, 39, 195-214.

Wolman, Alexander L., "Real Implications of the Zero Bound on Nominal Interest Rates," forthcoming Journal of Money Credit and Banking, 2004.

Woodford, Michael, Interest and Prices, Princeton: Princeton University Press, 2003. 


\begin{tabular}{lll}
\hline \hline Structural parameters & & \\
Downward nominal rigidity & $c(\pi<0)$ & 0 \\
Quarterly weight on output gap & $\alpha$ & 0.003 \\
Quarterly discount factor & $\beta$ & $\left(1+\frac{\bar{r}}{4}\right)^{-1} \approx 0.9913$ \\
Slope of AS relation & $\lambda$ & 0.024 \\
Real-rate elasticity of output gap & $\sigma$ & 6.25 \\
Degree of inflation indexation & $\theta$ & 0.99 \\
& & \\
Real-rate shock & & \\
Annually equilibrium value & $\bar{r}$ & $3.5 \%$ \\
Annually standard deviation & s.d. $\left(r^{n}\right)$ & $1.6 \%$ \\
AR(1)-coefficient & $\rho_{r}$ & 0.8 \\
\hline \hline
\end{tabular}

Table 1: Baseline calibration

\begin{tabular}{c|ccc}
\hline \hline $\bar{r}$ & Welfare-theoretic & Traditional & Equal weight \\
$3.5 \%$ & 79 & $<1$ & 10 \\
$2.0 \%$ & 189 & 4 & 53 \\
\hline \hline
\end{tabular}

Table 2: Optimal inflation buffer with lower equilibrium real-rate (b.p.s)

\begin{tabular}{c|ccc}
\hline \hline$c(\pi<0)$ & Welfare-theoretic & Traditional & Equal weight \\
& & & \\
0 & 79 & $<1$ & 10 \\
1 & 79 & 3 & 17 \\
\hline \hline
\end{tabular}

Table 3: Optimal inflation buffer with downward nominal rigidity (b.p.s) 

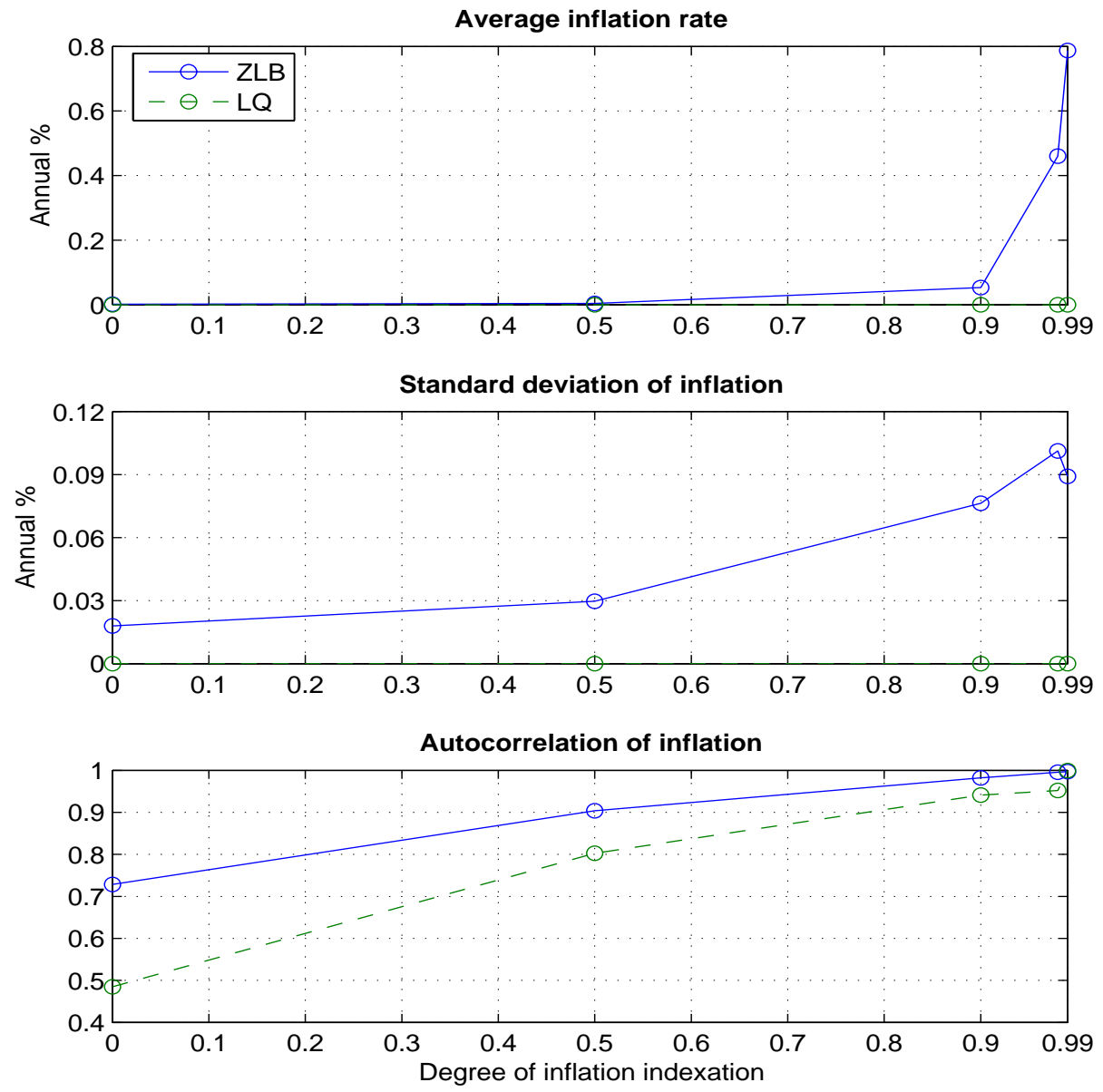

Figure 1: Stochastic distribution of inflation 


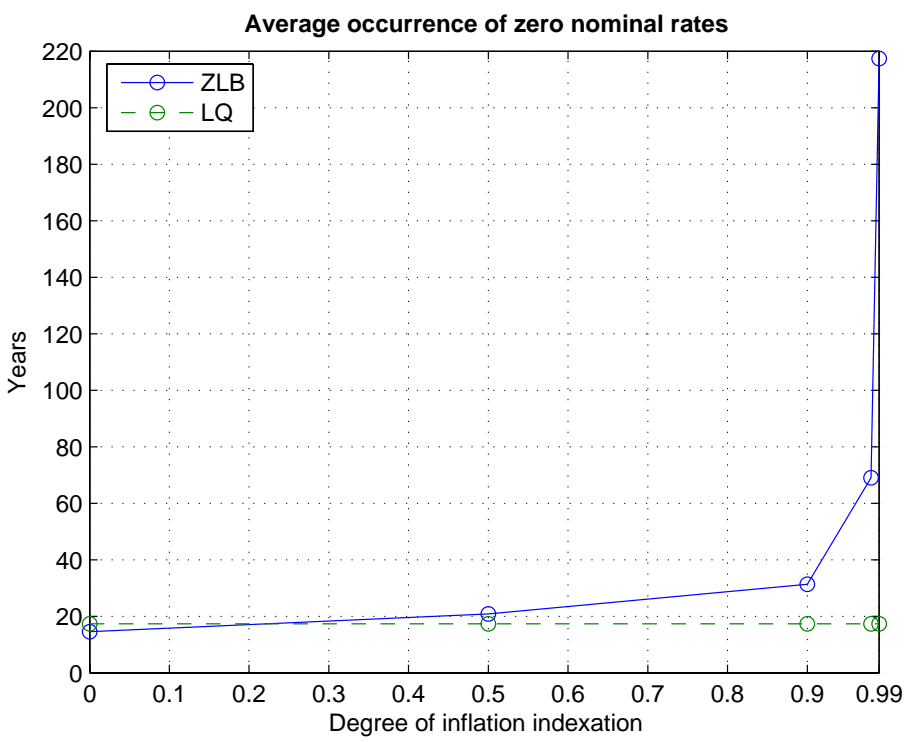

Figure 2: Frequency of zero nominal rates 

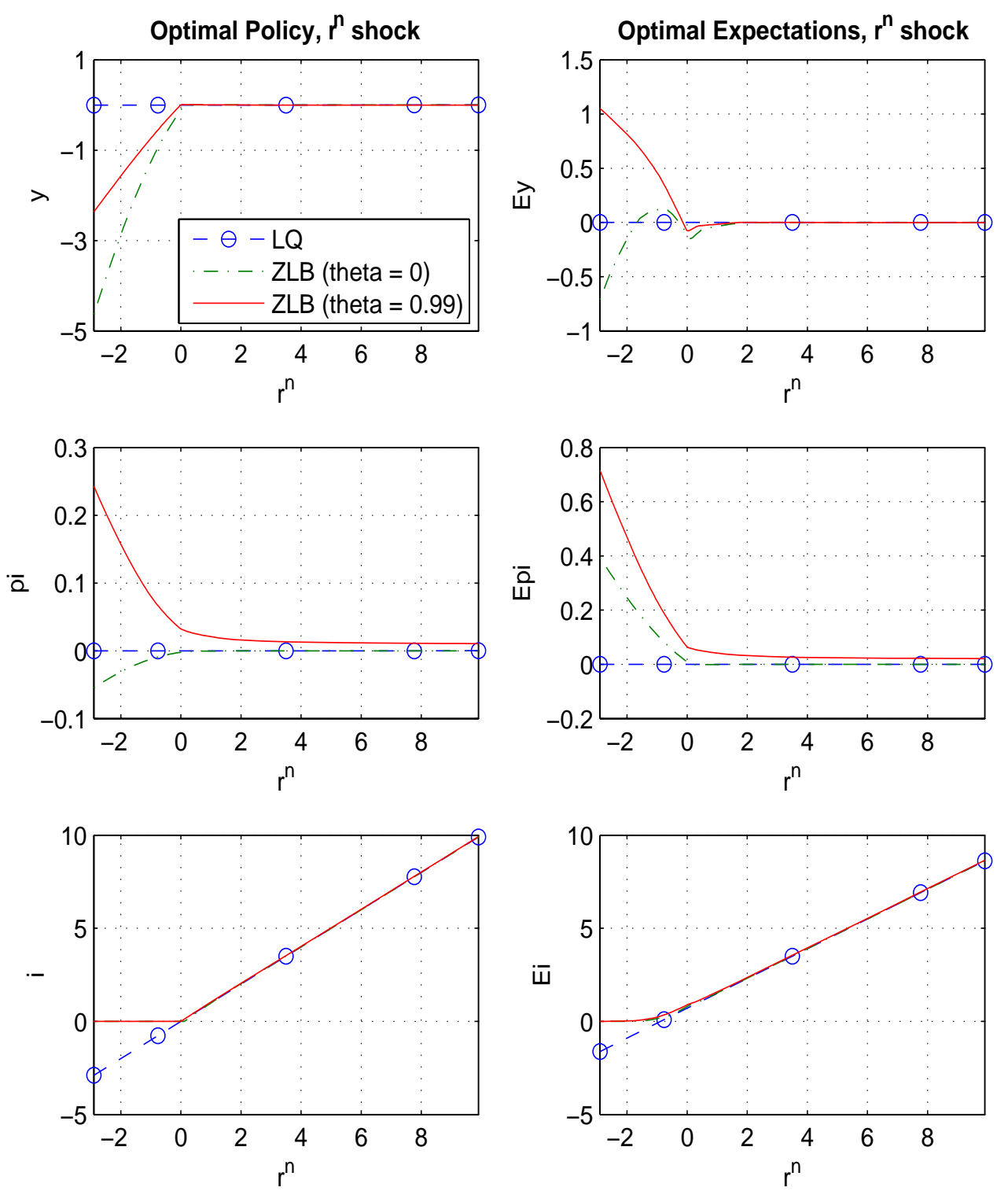

Figure 3: Optimal policy responses to real-rate shocks 

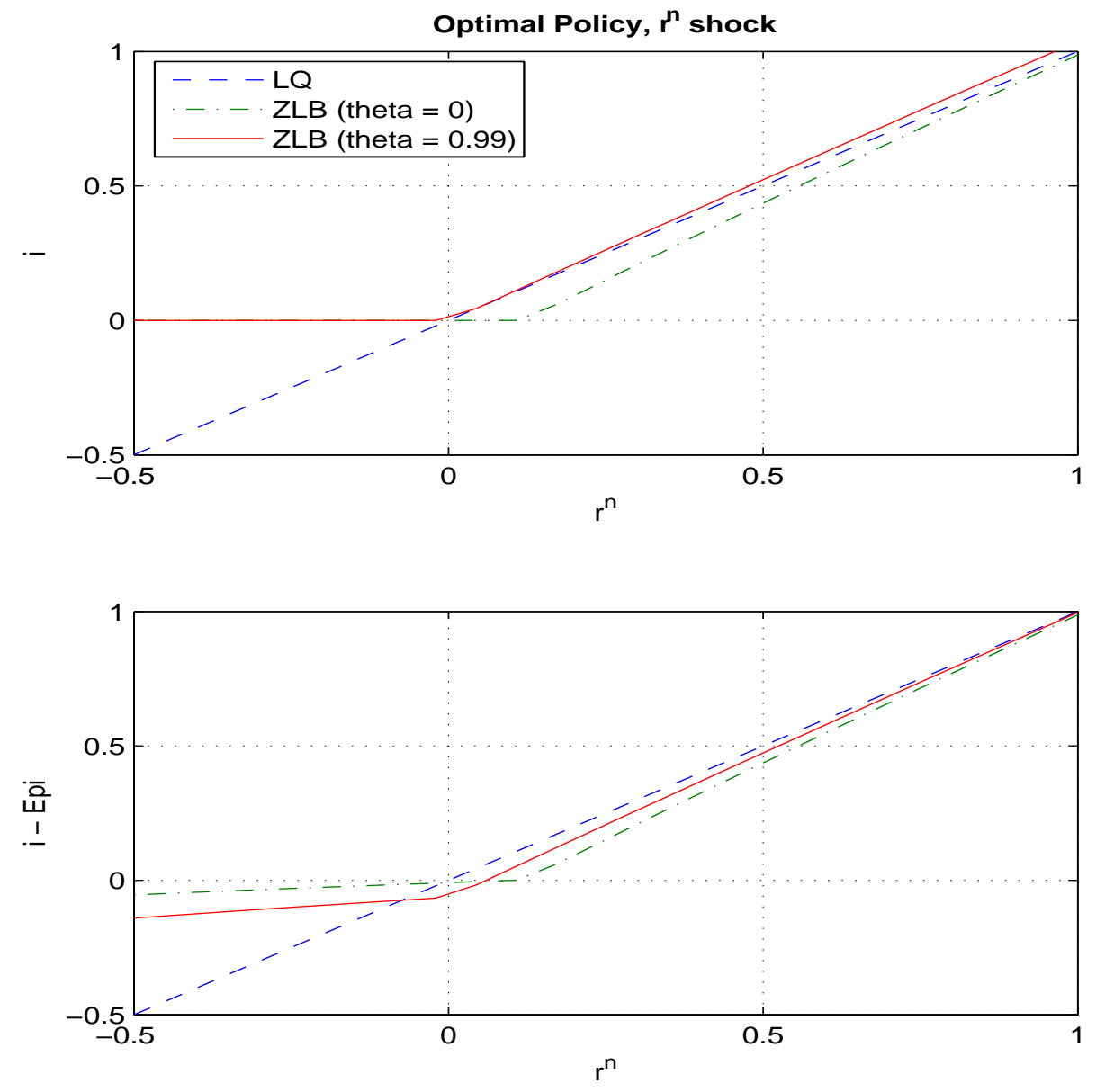

Figure 4: Preemptive easing 

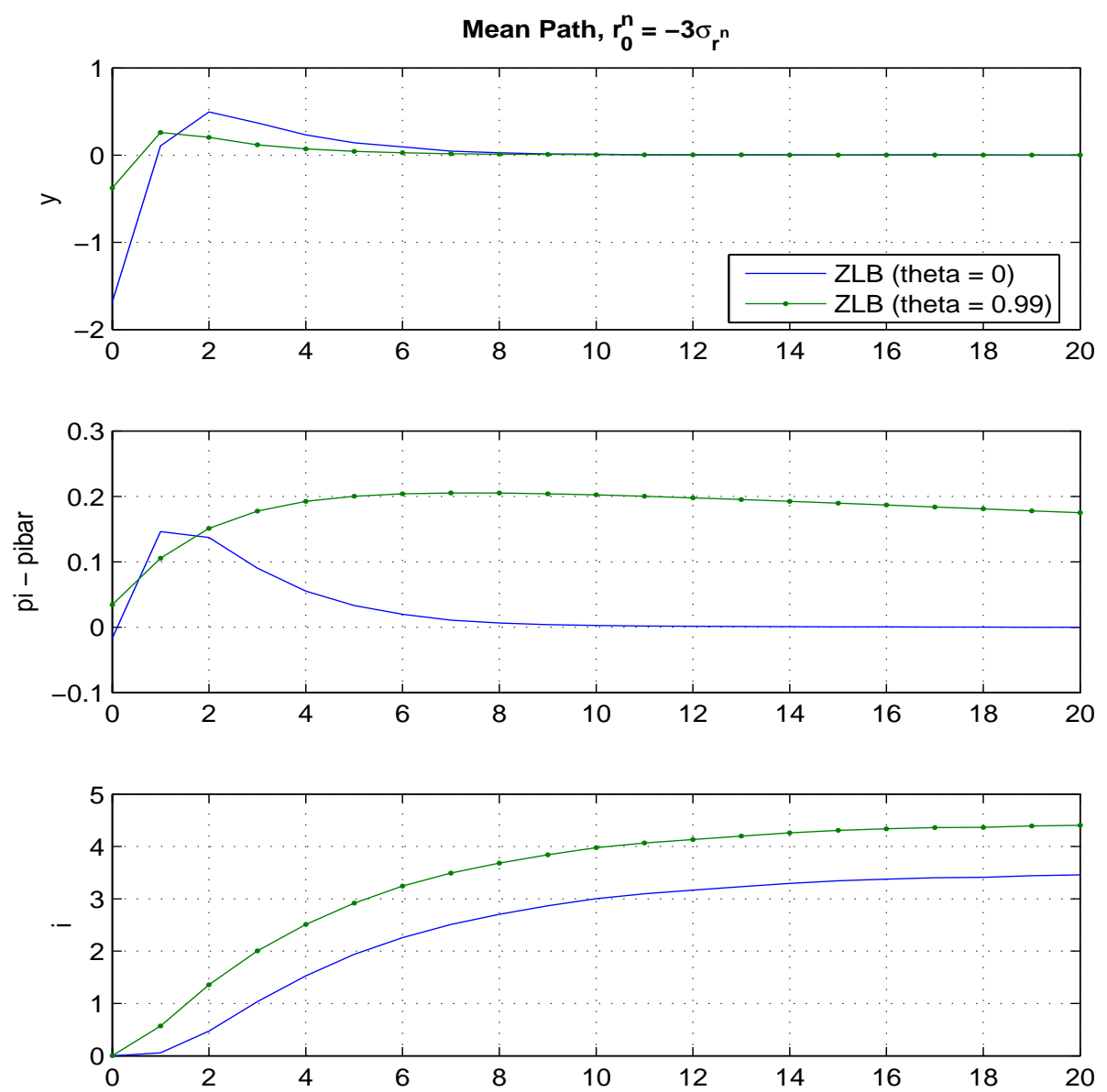

Figure 5: Mean responses to real-rate shocks 

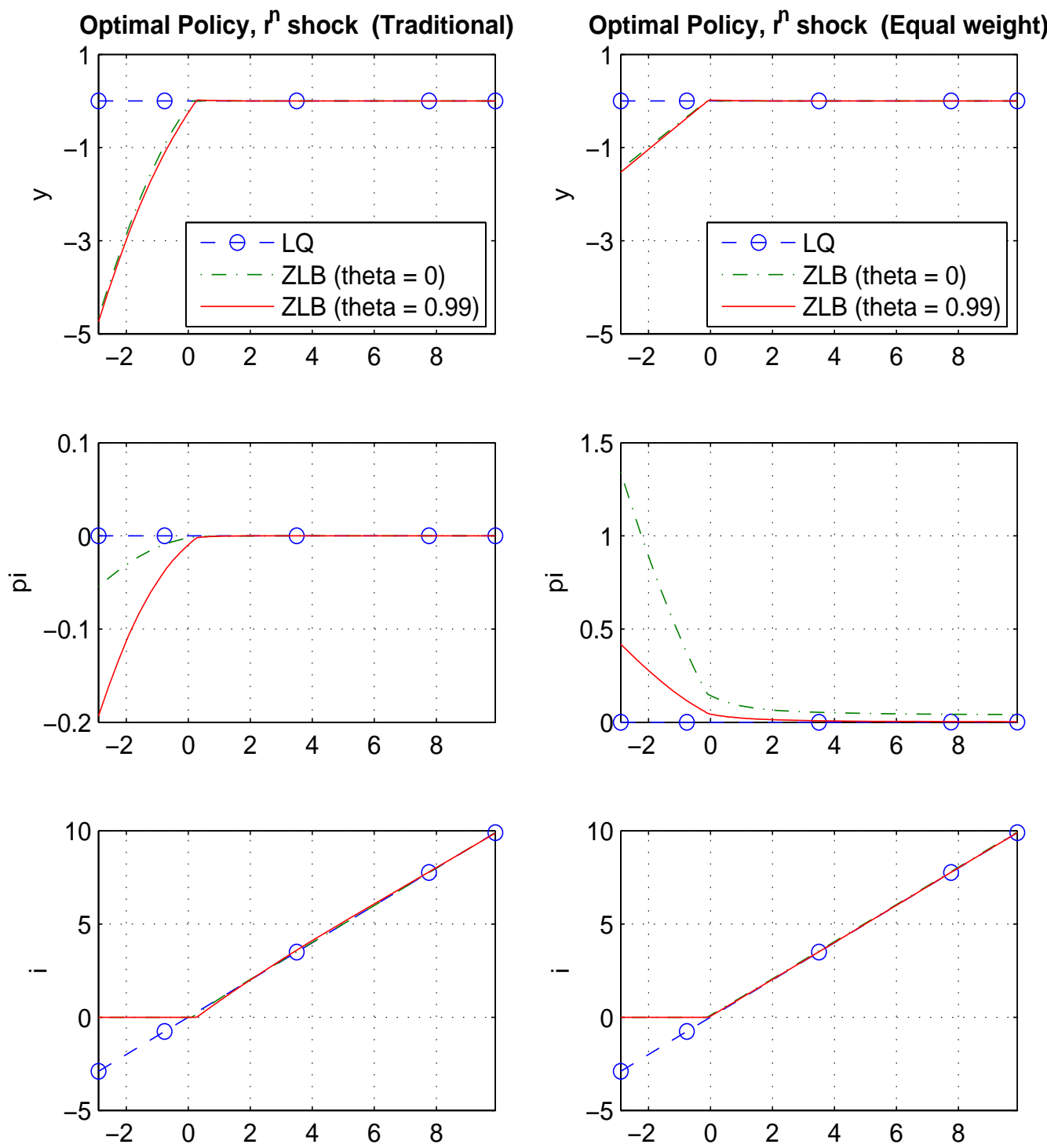

Figure 6: Optimal policy responses (Alternative loss function) 

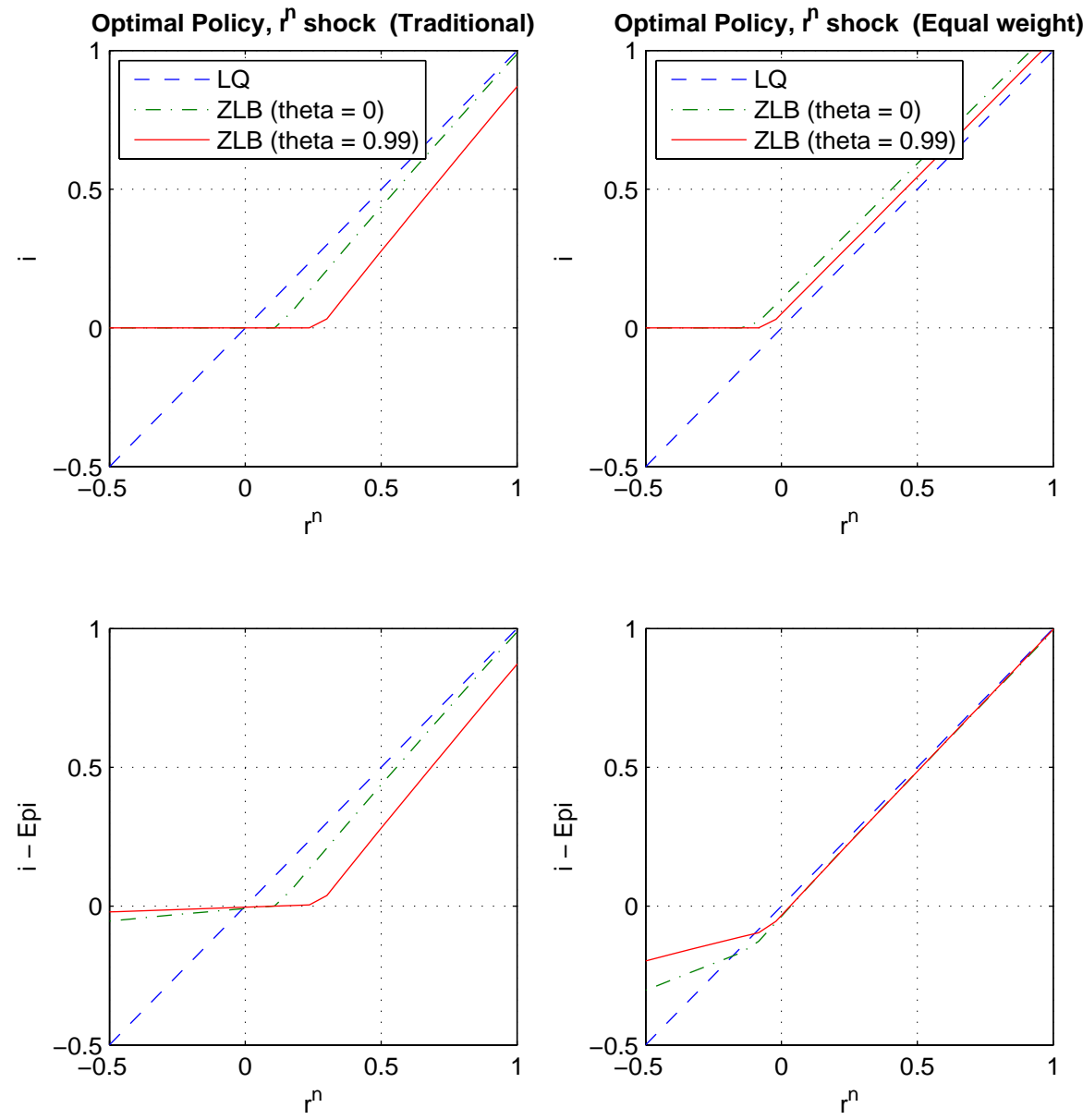

Figure 7: Preemptive easing (Alternative loss function) 

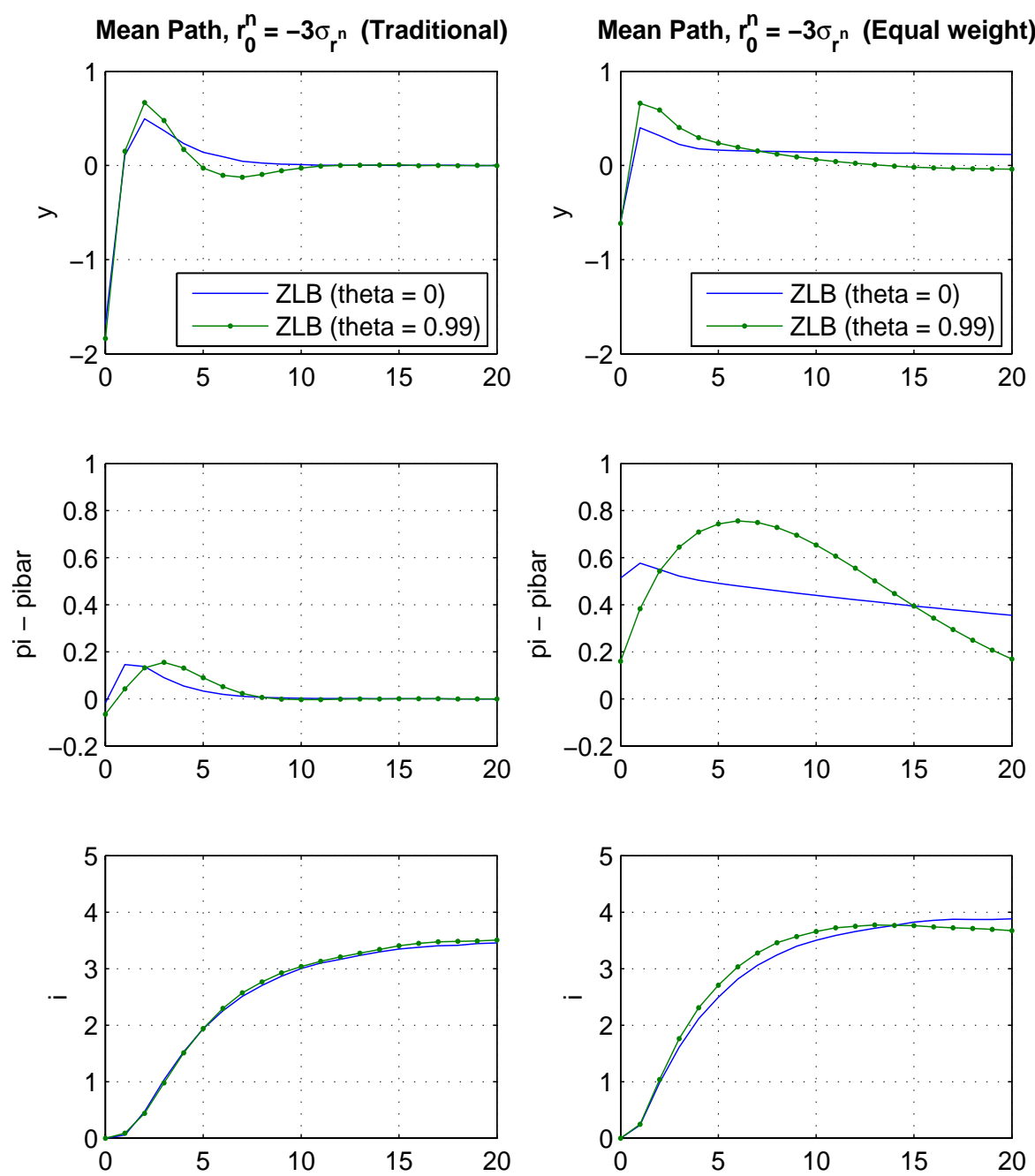

Figure 8: Mean responses (Alternative loss function) 


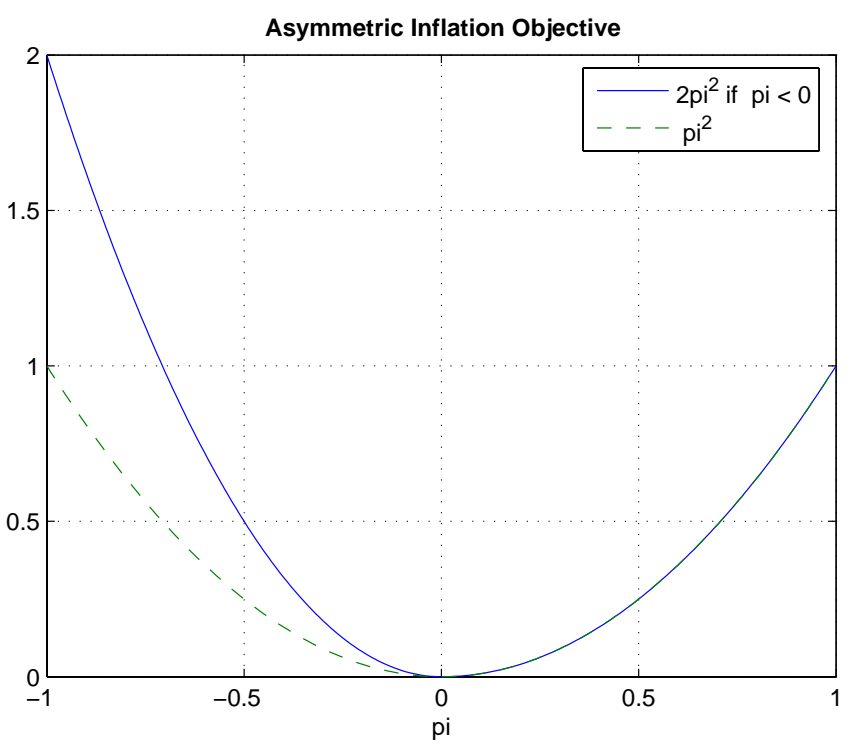

Figure 9: Downward nominal rigidity 


\section{CFS Working Paper Series:}

\begin{tabular}{|c|c|c|}
\hline No. & Author(s) & Title \\
\hline $2005 / 08$ & $\begin{array}{l}\text { Torben G. Andersen } \\
\text { Tim Bollerslev } \\
\text { Peter F. Christoffersen } \\
\text { Francis X. Diebold }\end{array}$ & Volatility Forecasting \\
\hline $2005 / 09$ & $\begin{array}{l}\text { Markus Haas } \\
\text { Stefan Mittnik } \\
\text { Bruce Mizrach }\end{array}$ & $\begin{array}{l}\text { Assessing Central Bank Credibility During the } \\
\text { ERM Crises: Comparing Option and Spot Market- } \\
\text { Based Forecasts }\end{array}$ \\
\hline $2005 / 10$ & $\begin{array}{l}\text { Juan Carlo Conesa } \\
\text { Dirk Krueger }\end{array}$ & $\begin{array}{l}\text { On the Optimal Progressivity of the Income Tax } \\
\text { Code }\end{array}$ \\
\hline $2005 / 11$ & $\begin{array}{l}\text { Markus Haas } \\
\text { Stefan Mittnik } \\
\text { Marc S. Paolella }\end{array}$ & $\begin{array}{l}\text { Modeling and Predicting Market Risk With } \\
\text { Laplace-Gaussian Mixture Distributions }\end{array}$ \\
\hline $2005 / 12$ & $\begin{array}{l}\text { Dirk Krueger } \\
\text { Felix Kubler }\end{array}$ & $\begin{array}{l}\text { Pareto Improving Social Security Reform when } \\
\text { Financial Markets are Incomplete!? }\end{array}$ \\
\hline $2005 / 13$ & $\begin{array}{l}\text { Keith Kuester } \\
\text { VolkerWieland }\end{array}$ & $\begin{array}{l}\text { Insurance Policies for Monetary Policy in the Euro } \\
\text { Area }\end{array}$ \\
\hline $2005 / 14$ & $\begin{array}{l}\text { Berc Rustem } \\
\text { Volker Wieland } \\
\text { Stan Zakovic }\end{array}$ & $\begin{array}{l}\text { Stochastic Optimization and Worst-Case Analysis } \\
\text { in Monetary Policy Design }\end{array}$ \\
\hline $2005 / 15$ & $\begin{array}{l}\text { Dirk Krueger } \\
\text { Fabrizio Perri }\end{array}$ & $\begin{array}{l}\text { Does Income Inequality Lead to Consumption } \\
\text { Inequality?Evidence and Theory }\end{array}$ \\
\hline $2005 / 16$ & $\begin{array}{l}\text { Klaus Adam } \\
\text { Roberto Billi }\end{array}$ & $\begin{array}{l}\text { Discretionary Monetary Policy and the Zero Lower } \\
\text { Bound on Nominal Interest Rates }\end{array}$ \\
\hline $2005 / 17$ & Roberto Billi & $\begin{array}{l}\text { The Optimal Inflation Buffer with a Zero Bound on } \\
\text { Nominal Interest Rates }\end{array}$ \\
\hline
\end{tabular}

Copies of working papers can be downloaded at http://www.ifk-cfs.de 